\title{
Replies to the Comments of Angela Breitenbach, Konstantin Pollok and Janum Sethi
}

\author{
ERIC WATKINS \\ University of California, San Diego \\ Email: ewatkins@ucsd.edu
}

I would like to thank Janum Sethi, Angela Breitenbach and Konstantin Pollok for their insightful and probing comments on my book. ${ }^{\mathrm{I}}$ They are the kind of comments that every author hopes to receive. Before replying, I offer a precis of my book.

\section{Precis of Kant on Laws}

It is a striking fact that Kant employs the notion of 'law' in many different contexts. In physics, for example, he is interested in formulating and justifying laws of mechanics in the Metaphysical Foundations of Natural Science, and he makes use of Newton's law of universal gravitation there and in his main argument in the Universal Natural History and Theory of the Heavens. But Kant also commits himself to laws of nature more generally in the Critique of Pure Reason, such as those expressed in the Analogies of Experience which govern all spatiotemporal appearances and not just the mechanical interactions of bodies. Then, in the second part of the Critique of the Power of Judgement, he devotes considerable attention to reconciling mechanical laws with biological phenomena that we experience as operating according to principles that seem to be inconsistent with the laws of mechanics. Thus, like many of his contemporaries, Kant thinks that natural science is essentially concerned with establishing laws of nature that determine everything that happens in the world, both large and small, and given the rich diversity of phenomena that we experience in the world, it stands to reason that we will need to appeal to a plurality of kinds of laws of nature (in physics, chemistry, biology, etc.). Given this, it is not surprising if these different kinds of laws of nature may apply to different domains, where some will be more specific and others more general, and may work in different ways - e.g. some may prove to be necessary as principles that constitute any possible experience, while others will serve as principles that are regulative for experience. 
However, Kant does not restrict the notion of law to laws of nature in his theoretical philosophy, but extends them to his practical philosophy as well. For not only does he articulate a framework within which political laws would be justified in the Doctrine of Right of the Metaphysics of Morals, but he also argues that our moral obligations must be conceived of in terms of a single principle that he characterizes as the moral law, in contrast to, say, Hume who makes no mention of a moral law. Again, the moral law applies to different cases in different ways insofar as it takes on imperatival form for human beings, who are subject to sensible desires that tempt us to transgress the demands of the moral law, whereas it does not take on such a form for purely rational beings, such as God, who are not subject to the vagaries of sensibility. The net result is that Kant employs the concept of law in both his theoretical and his practical philosophy, in the guise of laws of nature and the moral law.

What is more, in his critical period, he ends up attributing fundamental systematic importance to the notion of law. Near the end of the first Critique, in the Architectonic chapter, he notes: 'the legislation of human reason (philosophy) has two objects, nature and freedom, and thus contains the law of nature as well as the moral law, initially in two separate systems, but ultimately in a single philosophical system' (A840/B868). ${ }^{2}$ Though I return to further aspects of this passage below, it is clear that Kant is thinking of laws here as the a priori principles that lie at the foundation of his metaphysics of nature and metaphysics of morals and thus of his entire philosophical system.

Kant on Laws pursues two main goals. First, it provides detailed accounts of several different kinds of laws that appear in Kant's philosophy, attending to the specific nature and domain of each kind of law and the context in which it is relevant. Second, it articulates a generic concept of law that is instantiated in many of the different kinds of laws that play a significant role in Kant's philosophy. Though I think that both goals are equally important and that either one would be seriously incomplete without the other, in this compact summary I focus most of my attention on the second goal. The first goal can be best appreciated on the basis of the particular accounts that can be found in each of the chapters that discuss the details of each kind of law.

Now it is admittedly tempting, at least at first blush, to think that it is an accident that Kant uses the same term 'law' in the phrases 'law of nature' and 'moral law', given that they arise in quite different contexts (the Scientific Revolution in natural science as opposed to natural law theory 
in moral and political discussions). However, I argue that there is a single, univocal notion of law that underlies both of these uses, despite their different origins and despite the different uses to which they are put in his theoretical and practical philosophy. Specifically, the notion of law that is present in all these different contexts has two elements: (I) necessity and (2) the act of a spontaneous faculty whose legislative authority prescribes that necessity to a specific domain through an appropriate act. It is worth explaining each of these elements briefly.

The first element, concerning necessity, is important insofar as it distinguishes Kant's position from empiricist conceptions of law, which would be thoroughly contingent and are based on empirical events that are generalized in ways that, at least in principle, allow of exceptions. For Kant, by contrast, both the moral law and the laws of mechanics, to pick just two examples, are necessary in the sense that neither could have been otherwise. At the same time, it is important to note that this element of necessity can take on different forms in different cases. For example, even though the moral law is necessary for rational beings, it is not necessary that human beings act in accordance with it. Instead, Kant says that for us the necessity of the moral law takes the form of necessitation, or obligation, in the guise of a categorical imperative. The case of morality contrasts with, say, the Third Law of Mechanics, according to which every action necessarily has an equal and opposite reaction. When one billiard ball strikes a second, causing it to accelerate, the second billiard ball necessarily strikes the first, causing it to decelerate in equal measure. The changes of motion of the billiard balls are not the result of obligation, but rather of causal determination according to necessary laws. Despite the important differences between the cases, however, Kant's basic idea is that there is a necessity that grounds the moral obligation and the causal determination in each case.

The second element of Kant's generic notion of law derives from the idea that not every principle amounts to a law. Indeed, not even every necessary principle is a law. Instead, what makes a necessary principle into a law is the act of a legislator, for it stands to reason that there can be no law without a legislator enacting a principle as a law. This kind of position is not unique to Kant, as it can be viewed as part of the common sense meaning of the term 'law' and as stemming from the natural law tradition. What is distinctive of Kant's position, I argue, is the way in which he identifies our spontaneous faculties as legislators of the law. In his practical philosophy, drawing inspiration from Rousseau, he embraces his famous doctrine of autonomy, according to which reason legislates the moral law 
to itself. Analogously, in his theoretical philosophy, Kant argues that the understanding prescribes laws to nature (which are then, appropriately enough, called laws of nature). In both cases, a spontaneous faculty performs an act that results in something being a law. This feature of Kant's position fits nicely with those laws that he thinks of as regulative principles, since it is natural to think that prescriptions must have some valid or appropriate source; otherwise, one would have no reason think it proper that they should regulate our behaviour. This second element is thus present in the different kinds of laws that Kant acknowledges, just as the first is.

Kant on Laws argues for the two main goals identified above over the course of twelve chapters, grouped into five parts. Part I focuses on Kant's concept of law. The first chapter, 'What is, for Kant, a Law of Nature?', argues that Kant has a univocal concept of law that is employed in his account of laws of nature and the moral law, and it articulates the two main elements of that concept that are outlined above. It is foundational for the rest of the book. The second chapter, 'Kant on Transcendental Laws', argues that so-called transcendental laws, such as the Analogies of Experience, have a necessity that is based, at least in part, on our cognitive natures, which makes Kant's an attractive alternative to empiricist accounts (in virtue of the necessity it invokes) and to necessitarian accounts (in virtue of the natures it invokes being cognitive and in some sense accessible to us).

Part II focuses on the laws of mechanics, which are among those laws that are most important to Kant's views on natural science. The third chapter, 'The System of Principles', prepares the way for discussing the three Laws of Mechanics that Kant treats in the Metaphysical Foundations of Natural Science by providing an account of the more abstract transcendental laws that Kant argues for in the Critique of Pure Reason's System of Principles of the Pure Understanding. The fourth chapter, 'The Argumentative Structure of Kant's Metaphysical Foundations of Natural Science', describes how the more specific principles that Kant argues for in the Metaphysical Foundations, including the Laws of Mechanics, are related to those transcendental laws, and argues that Kant does not derive the former from the latter by way of simple substitution, but rather shows how the former are established by way of an extended transcendental argument, one that is based on the possibility not of experience in general, but rather of experience of matter as an object of outer sense. The fifth chapter, 'The Laws of Motion from Newton to Kant', presents an overview of how Newton's three Laws 
of Motion were received in eighteenth-century Germany. It provides crucial context for understanding the subtle but important differences between Newton's Laws of Motion and Kant's Laws of Mechanics, which are otherwise easily overlooked. With all of these aspects of Kant's position in place, chapter 6, 'Kant's Justification of the Laws of Mechanics', then provides a detailed interpretation and reconstruction of Kant's arguments for the three Laws of Mechanics, while also illustrating how his conception of law is instantiated in this crucial case.

Part III focuses on the nature and status of organisms, especially insofar as the kind of teleological considerations that are essential to understanding organisms contrast with mechanical laws. Chapter 7, 'The Antinomy of Teleological Judgement', considers the Thesis and Antithesis statements and arguments as they are presented in the Antinomy of Teleological Judgement in the Critique of the Power of Judgement, arguing that it remains difficult to understand exactly how Kant thinks that a supersensible ground can resolve the contradiction that is formed by those statements. Chapter 8, 'Nature in General as a System of Ends', discusses various teleological principles that Kant endorses, such as 'nothing in nature is in vain', 'nature is a system of purposes' and 'nature as a whole has a purpose', and shows how reason's reflections on organisms can support such principles.

Part IV considers how various laws can be regulative principles. The ninth chapter, 'Kant on Rational Cosmology', discusses the status of a series of principles that were typically classified as part of rational cosmology - the principles of no fate, no chance, no leap and no gap and shows that they are best understood not as principles Kant rejects as cases of dogmatic metaphysics, but rather as regulative principles that should be endorsed. Chapter ro, 'Kant on Infima Species', discusses the 'logical laws' of homogeneity, specificity and continuity, which are closely related to his claims in the Jäsche Logik that there can be no lowest species and no next species. It argues that Kant's justification for these principles is based not on the limitations of sensibility, as one might expect, but rather on the limitations that attach to our discursive understanding.

Part $\mathrm{V}$ takes a broader view of the notion of law, one that extends beyond Kant's theoretical philosophy to his practical philosophy and the moral law. Chapter II, 'Autonomy and the Legislation of Laws in the Prolegomena', points to deep parallels between the notion of legislation that Kant requires for legislating the laws of nature and the notion of 
legislation that he requires for legislating the moral law, while also acknowledging important points of contrast. In this context, it considers whether Kant's views on legislation, especially as articulated in the Prolegomena, influenced his views on autonomy and the legislation of the moral law, which first emerged in the Groundwork. In chapter I2, 'Kant on the Natural, Moral, Human, and Divine Orders', I argue against the view that by introducing the idea that human faculties legislate the law Kant must completely reject the traditional view according to which God is (in one way or another) responsible for both the laws of nature and the moral law. For even with his views of legislation in place, Kant has need of, and also constructs, an elaborate argument for the existence of God over the course of the three Critiques, one that allows for a prominent role for the divine order that is coordinated with the human and natural orders.

The Conclusion undertakes the important task of explaining how the diversity of laws discussed in the previous chapters is possible given the univocal notion of law that underlies them. It is one thing to explain the unity amidst the diversity, which the first chapter initiated, quite another to explain how diversity is possible with an underlying unity. Specifically, the concluding chapter argues that we can account for the diversity that we find in the nature, scope and kinds of laws to which Kant is committed by acknowledging that different faculties can perform different acts with respect to different objects and that reason, our most authoritative faculty, has certain interests and essential ends that allow laws to play essential and fundamental roles within his philosophy. In this way, the book, taken as a whole, shows us how we can understand both the unity and the diversity of laws within Kant's critical philosophy.

\section{Reply to Janum Sethi}

In her excellent comments, Janum Sethi raises three important questions for my account. First, is there for Kant any literal sense in which laws are prescribed to nature? Second, how can the account of laws of nature that I attribute to Kant be applied to empirical laws of nature? Third, how ought one to understand the immutability of our cognitive natures on which the transcendental laws of nature depend?

\section{Acts of Prescription}

Sethi asks how one should understand the act of prescription (or legislation) that is, on my interpretation, a necessary component of laws. She presses the point (implicitly) by way of the following dilemma. The acts of legislation in question are either the acts of particular individuals at 
particular moments in time on particular occasions, or they are not. If they are, then there is a literal sense in which they can be understood as acts of legislation. If they are not, then they are acts of legislation only in a metaphorical sense. She then argues that the first horn of the dilemma is untenable, and thus infers that one can speak of acts of legislation only in a metaphorical sense.

Now I wholeheartedly agree that the first horn of the dilemma must be rejected. This is even more clearly the case when we think of the moral law. ${ }^{3}$ If the validity of the moral law were to depend on particular individuals legislating it on particular occasions, it would be possible to avoid the imperatival force of the moral law, which is supposed to be categorical and thus unavoidable. But similar objections can be raised to attempting to understand the legislation of the laws of nature in analogous fashion. If causal laws were to depend on the particular acts of particular individuals at particular times, one could avoid undesirable effects (such as coercion) simply by not legislating the law that would bring about such effects.

However, I do not accept the second horn of the dilemma because the notion of an act does not have to be tied to an individual at some particular time. There is a thinner, non-empirical notion of an act that does not require temporal particularity in the way in which empirical acts do, but that is also not merely metaphorical. That is, some acts may occur at particular times, but it does not follow that every act has to occur at a particular moment of time, or that what it is that makes something an act is the fact that it occurs at a particular moment of time. It may help here to think about space and time. As an empirical individual, I have my particular representation of space and time, and you, as the particular empirical individual you are, have your particular representation of space and time. While we are both viewing the world spatially and temporally, we do so from different points of view such that my particular representation of an object in space is not literally the same as your particular representation of that object in space. Yet it is clear that, on Kant's view, there are single a priori representations of space and time that we both have. Admittedly, these representations do not involve acts of legislation by the understanding or reason, but rather are formed by way of sensibility. However, the important point here is that there is a more generic and thinner notion of a priori representation that is not datable to some specific empirical moment of time, even if there are tokens of that kind of representation that occur at particular moments of time. An analogous point can be made about the categories and thus about laws of nature. 
Even if I apply the category of causality and the causal law associated with it on a particular spatiotemporal occasion so as to cognize a particular event and you do the same on a different spatiotemporal occasion, there is still a legitimate sense in which we are applying the same category and thus legislating the same causal law. Indeed, this must be the case if we are ever to cognize the same event, despite our numerically distinct representations. Further, it is no metaphor to say that we share the same a prior $i$ intuitions and categories even though we have different empirical intuitions and concepts, since these presuppose shared a priori intuitions and categories. Similarly, it is no metaphor to say that there are acts of legislation that are embedded in the categories.

A second point that may help one understand how an act of legislation or prescription can be independent of determinate spaces and times and not reduce to metaphor is to recall that both Leibniz and Kant conceive of substantiality in terms of activity. For both, something cannot be a substance without being active, which means that every substance necessarily acts, whether or not it exists in space and time. Accordingly, God, as a perfect and most real being, must act. Further, it is tempting, at least for Leibniz and Kant, to think of God as creating the finite substances that constitute the world (including us) and as one who issues the moral law as a divine command. On such a view, we cannot conceive of God's acts of creation and legislation as occurring at particular spatiotemporal locations. Similarly, on Kant's view as I understand it, insofar as there are things in themselves that affect us, giving rise to sensations that we take up into empirical intuitions, that act of affection cannot be in time. The content of this broadly applicable notion of act would have to be represented by way of an unschematized category, and thus be rather thin and unlike that of our notion of those (empirical) actions that we consciously perform in our day-to-day lives and represent by means of schematized concepts. However, if there is a core content to the notion of an act that can be instantiated in different contexts, as must be the case for Kant in light of his commitments to what we can think (without cognizing), one can conceive of acts of legislation or prescription as acts that beings endowed with the appropriate faculties can perform. But if we can accept such a notion of an act, then we can avoid the dilemma that Sethi poses, as there is an intelligible and non-metaphorical notion of an act to which Kant is committed but that is not empirical and not datable to particular places and times.

If one can understand Kant's position in this way, the question remains as to whether one should do so. One reason to interpret Kant's notion of law 
in terms of acts of legislation is textual. Recall one crucial passage from the Prolegomena, in which Kant remarks: 'even though it sounds strange at first, it is nonetheless certain, if I say with respect to the universal laws of nature: the understanding does not draw its (a priori) laws from nature, but prescribes them to it' ( $P, 4: 3$ I9-20; emphasis in the original). Kant explicitly admits, indeed emphasizes, that the doctrine he is asserting sounds strange, but he commits to it despite its strangeness. Why would Kant select the term 'prescription' if it were meant metaphorically rather than literally? Instead of choosing a metaphorical term that makes it more difficult for readers to accept his position, he ought to have chosen one that would not draw attention to (purportedly) undesirable features of his view. For this reason, the most plausible way to understand the sentence is as making a claim that is meant to be literally true. Nor can one dismiss this sentence as an isolated occurrence. As we saw in the passage from the Architectonic quoted above, Kant does not simply say that there are two distinct but ultimately related objects of special philosophical importance, nature and freedom; instead, he claims that human reason legislates these two objects in the guise of laws of nature and the moral law. This kind of passage is especially friendly to my interpretation because the parallel between the theoretical and the practical is made explicit, as is the idea that legislation is required for the kind of law that is relevant to nature and freedom. ${ }^{4}$ Indeed, once one starts looking, one can find this kind of terminology scattered throughout Kant's corpus. See e.g. the Introduction to the Critique of the Power of Judgement where he claims that our cognitive faculty has two domains, nature and freedom, and it is ' $a$ priori legislative through both' (CJ, 5: I74). The textual evidence in favour of reading Kant as committed to acts of legislation is widespread.

Another reason to interpret Kant's position in this way is philosophical. One might think that even if Kant's commitment to the language of legislation is clear, it is still best understood as merely metaphorical. However, there are philosophical costs to any interpretation that views his use of the term 'legislation' as purely metaphorical. For one, it would be necessary to clarify what the metaphor is supposed to stand for. Karl Ameriks and Konstantin Pollok have suggested (independently) that Kant is using legislation talk to say that we must 'appreciate' or 'acknowledge' the normativity of these laws. ${ }^{5}$ But such epistemic terms are insufficient on their own, as they presuppose that the principles that are being appreciated or acknowledged are in fact binding, and without any account of how they can be binding, it is unclear that a stance of appreciation or acknowledgement is appropriate. ${ }^{6} \mathrm{~A}$ literal rendering of acts of legislation, by contrast, 
provides a clear account of the binding force of the moral law and, strange as it might sound, of laws of nature too insofar as they are supposed to govern appearances and not simply be true descriptions of appearances. In short, if one omits reference to acts of legislation in the literal sense, one will be under pressure to abandon any literal talk of laws of nature and the moral law in favour of non-governing descriptions of worldly events and moral principles.

Such an interpretation also risks endangering the systematic unity that is a hallmark of Kant's philosophy. For on Kant's picture, we have, along with our spontaneous faculty of reason, a single set of unifying functions that bring about unity and order. Without acts of legislation that impose this unity on whatever multiplicity is given to us, there would be no unity, and without unity, no systematicity. While one could adopt a position that simply acknowledges different metaphysical and normative constraints that lack any unifying principle, it would be a much less attractive and intelligible position than the one that supports Kant's systematic philosophical thought. Thus, philosophical grounds provide additional support for a literal interpretation of legislation.

\section{Empirical Laws of Nature}

Sethi rightly notes that I do not present a detailed account of Kant's views on empirical laws of nature. The topic, which involves a number of metaphysical, epistemological and scientific issues, is notoriously complicated and deserves a book-length treatment of its own. All I can do here is briefly indicate a few markers of some of the main lines of what I take Kant's view to be.

In Kant and the Metaphysics of Causality (Watkins 2005), I argued for, among other things, the view that laws of nature are based on the natures of things. Specifically, on my interpretation, the intrinsic properties of things that constitute their natures are (partial) grounds of the laws, where the laws determine the states of these things when they interact according to their respective natures and circumstances. In Kant on Laws I then argued that the laws of nature also depend on our cognitive capacities, including our understanding's act of prescription. These acts of prescription are thus (partial) grounds of the laws of nature as well. In filling out this account, I suggested that the natures of things are (partial) grounds of the content of the laws, while our understanding's act of prescription is a (partial) ground of the lawfulness of the laws of nature. 
Sethi asks for clarification of how what is due to the understanding is supposed to be related to what is derived from the natures of the objects that the laws govern when they interact. One point of clarification derives from the fact that Kant's position is informed by his distinction between matter and form. ${ }^{7}$ The matter of the empirical laws of nature, the specific empirical content that varies from one empirical law to another, is grounded in the empirical natures of whatever objects the laws of nature govern. The laws of chemistry, for example, are based on the different kinds of chemical elements, and, more generally, what distinguishes empirical laws from the a priori laws treated in the System of Principles is that the former hold only for objects that have a specific nature, whereas the latter hold for all objects, regardless of the kind of nature they might have as long as they are objects of experience. By contrast, the form of empirical laws - their conformity to law, the lawfulness of the laws, or the fact that this object will always act in the same lawful way - is grounded by the understanding.

If we can identify the form and the matter of empirical laws in this way, how do they interact? Though Kant applies the form-matter distinction in different ways in different contexts, its basic idea is that the matter is the determinable, while the form is what determines the determinable such that it is then determinate. What this means in the current context is that, through its act of prescription, the understanding determines the specific natures of things in the sense that, despite their necessity and their particularity and the differences that they may have from each other as a result, they take on a universal form in the guise of empirical laws of nature that hold for those things over all instances. That is, though the nature of each thing is particular - each thing is the particular thing that it is and has whatever particular nature it has - it is the understanding that renders that thing's content universal, and it does so by relating that particular to others such that they will always relate to each other in the same way, rather than simply apprehending that particular as a particular (as a divine intellect might). It is worth noting that there are similarities between the questions that this account faces and those that one encounters in attempting to explain Kant's account of empirical concept formation. For in both cases, the understanding starts with some material particular (sensation/empirical intuition and particular empirical nature) and, somehow, forms from it something universal (an empirical concept or an empirical law of nature).

A second point of clarification, related to the first, derives from the complex logical and real conditioning relations that empirical laws of nature 
stand in. Every empirical law will have its place within a system of empirical laws, where some are narrower and more restricted in their scope as others are broader and less restrictive. If these empirical laws are related in the form of logical conditioning relations, as premises and conclusions within a series of syllogisms, they can form part of natural science proper. But note that what makes a body of cognitions science proper is not that they can be put into a certain logical form, but that they can explain why events happen the way they do; the laws of nature are supposed to capture the reasons for what happens, but they can do that only insofar as they somehow express those real conditioning relations between things that explain why they come to be in the states that they are in. For example, the fact that human beings are mortal is not explained by the fact that it follows logically from the fact that animals are mortal and human beings are animals. Instead, human beings are mortal because each one of us dies, and there is a cause of death that varies from case to case, at least in its specifics. The job of (medical) science is to explain the causes of death of each individual as well as the general laws that must in some way cover the particular causes of death. Accordingly, while reason must make sure that any conclusion it draws does follow logically from its premises, with the help of the understanding it must also grasp the real conditioning relations in the world and determine the more general ones before they can be put in a final logical form that could be called science proper. And here it is to be noted that reason cannot do its job without the understanding grasping the natures of things as part of the ground of the laws of nature that can then be placed in the kind of logical conditioning relations that are required for science. This is obviously not a complete account of empirical laws of nature, but it does point in two important directions for further clarification.

\section{Immutability}

In chapter 2 , in the course of explaining the special status that transcendental laws of nature have for Kant, I compare and contrast his view with Carnap's, which invokes the notion of the 'revisable a priori'. Distinctive of Kant's account, I argue, is the necessity of the natures of our cognitive faculties which supports the necessity of transcendental laws, in contrast to the contingency of laws on Carnap's account. In a footnote, I suggested that even if one did not insist on the necessity of our cognitive natures, there could still be an important difference with Carnap's position, given that Carnap's laws depend on ultimately arbitrary choices of linguistic frameworks, rather than on our cognitive natures (whether immutable or not). Sethi quotes one passage from Kant (BI 67-8) that gives expression to the importance of the necessity of our cognitive natures, before 
asking what grounds Kant's claim that our cognitive natures are immutable. In support of this question, she cites a second passage (BI45-6), where Kant claims that we are unable to explain why our understanding must use the twelve categories that we have to bring about the unity of apperception, just as we cannot explain why space and time are our forms of sensible intuition.

It is important to keep two issues distinct here, though the one depends on the other on Kant's view. The first concerns the modal question of whether our cognitive natures are immutable and necessary, and if so, of whether we can provide any explanation of their necessity. The second concerns the explanatory role that our cognitive natures play in Kant's account of transcendental laws, and concerns explanatory or grounding rather than modal relations (though grounding relations may involve modal relations). As for the first question, I take it that for Kant the kind of self-cognition that reason arrives at after conducting its analysis of our cognitive faculties reveals the natures of our cognitive faculties and their necessity. Consistent with this, he repeatedly remarks that we cannot explain why we have space and time as our forms of sensibility and the categories as our discursive forms of thought and understanding. If they are brute or unconditioned necessities, as Kant thinks they are, then it makes sense that we cannot explain them, as there is nothing to explain, and reason has to rest content with the fact that it has uncovered their distinctive fundamental natures. As for the second question, not only can we not explain why we have a discursive understanding, with the twelve categories listed in the table of categories, but I take it that, according to this passage, we also cannot explain why we have to use these categories to bring about the unity of apperception rather than in some other way. That is, the categories have the features that are necessary to produce the requisite result, but even if we could explain the necessity of the understanding and its categories, that would still not amount to an explanation of why, for example, there could not be other representations (which we do not have) that could produce the same result. Accordingly, there are limits not only to what we can explain about the necessity of our cognitive natures, but also about what we can explain in the course of the explanations that invoke them to further ends.

\section{Reply to Angela Breitenbach}

In her rich comments, which are a model for their remarkable combination of clarity and charity, Angela Breitenbach expresses fundamental agreement with several features of my interpretation of Kant's principles of homogeneity, specification and continuity (articulated in chapter Io), 
before offering some critical remarks that could be taken as a friendly amendment, and then showing how they might support a broader conception of reason, one that emphasizes systematic unity rather than an unconditioned condition. In reply, it is certainly tempting simply to accept both the friendly amendment and the broader conception of reason that Breitenbach sketches, especially since the amendment can seem to eliminate an asymmetry in Kant's position that is otherwise difficult to account for. At the risk of appearing ungrateful, let me express some further thoughts.

What I am calling a friendly amendment is Breitenbach's proposal that one accept my interpretation of the principles of homogeneity, specificity and continuity as expressing the interests of reason, but restrict its scope to empirical concepts. She notes that my interpretation takes some of Kant's remarks about lowest and next species in the Jäsche Logik to be directly relevant to his discussion of the principles of homogeneity, specification and continuity in the Appendix to the Dialectic, and one could cast doubt on such a connection, either because the Jäsche Logik is not a reliable account of Kant's views or due to scepticism that Kant's discussion of lowest and next species is really relevant to the Appendix's regulative principles. But there are significant reasons that speak in favour of Breitenbach's restriction of these regulative principles to empirical concepts. For one, it is much easier to maintain that there is no highest empirical concept than it is to maintain that there is no highest concept, at least as a textual matter, given that Kant explicitly refers to the concept of 'possible thing' as a highest concept in his logic transcripts (but see also A290/B346). For another, the very argument that I use to establish that there can be no lowest concept would seem to establish, by parity of reasoning, that there can also be no highest concept. These are serious reasons and, taken together, they represent a serious temptation. If Kant's assertion that there is a highest concept were the only consideration that motivated the asymmetrical view I proposed, Breitenbach's restriction of the view to empirical concepts would likely be the strongest interpretation, because it could accommodate that fact while still allowing for a thoroughly symmetrical account of empirical concepts and the relevant regulative principles.

However, Kant's assertion of the existence of a highest concept is not the only reason that speaks in favour of taking the regulative principles to range over all rather than only empirical concepts. For at least some of the arguments that support the principles of specification (no lowest species) and continuity (no next species) were based on logical relations of 
conceptual containment, which are perfectly general. If one concept contains another, it does so regardless of whether they are empirical or $a$ priori concepts. And if I abstract from some of the content of one concept so as to form a more general one that contains it, this act of abstraction is possible whether or not the concepts in question are empirical. Since the considerations on which the arguments for the regulative principles are based are not limited to empirical concepts, if they are compelling, they should be so for both empirical and non-empirical concepts.

At the same time, while reason is interested in the logical relations between concepts, it is also true, as is clear from my response to Sethi, that reason is interested in the real conditioning relations between things, and insofar as concepts are supposed to capture the content of things, reason must be interested in their real relations as well. Accordingly, because concepts must be formed so as to be attentive to the real relations they are representing, reason cannot rest content with purely symmetrical logical relations. Thus to know what one should think about the principles of homogeneity, specification and continuity, which are logical principles that reason uses in the hope of discovering real relations, one would need to have a detailed view of real conditioning relations as well as the relations between them and the kind of logical conditioning relations that are implicit in, or can be expressed through, the hierarchical structure of concepts. This remains a desideratum in Kant scholarship.

But what of Breitenbach's suggestion that the regulative principles of homogeneity, specification and continuity are better supported by a conception of reason that emphasizes systematic unity rather than a search for unconditioned conditions? Even if I hold off, for the time being, on accepting her friendly amendment regarding whether the regulative principles in question hold only for empirical concepts, the conception of reason that she points to could be accepted on independent grounds. Here it is important first to distinguish between reason's interest in what is unconditioned and its interest in the totality of conditions. Especially when regulative principles are at issue, reason is more immediately interested in the latter because if it could find all of the relevant conditions, it would thereby also have found the unconditioned. Though there is a conceptual difference between the notion of a totality of conditions and that of the unconditioned condition, Kant thinks it legitimate to infer from the former to the latter $\left(\mathrm{A}_{4} \mathrm{I}_{7-\mathrm{I}} 8 / \mathrm{B}_{445}\right)$. What is more, it is clear that both the unconditioned and the totality of conditions are distinct from the kind of systematic unity that Breitenbach is drawing our attention to, one that includes not only whatever unconditioned conditions there are, but 'the 
entire system taken as a whole', where such a system is to be understood in teleological terms as realizing an 'idea' in Kant's technical sense.

There is much to be said in support of Kant's notion of systematic unity, especially when it comes to identifying an argument that would justify the principles of specification and continuity. For these two regulative principles push the understanding, not toward the top, as the principle of homogeneity does, but rather toward the bottom and middle, such that, taken together, these three regulative principles push in every possible direction. In fact there are, I think, crucial connections between Kant's conception of reason as the faculty that seeks cognition of the totality of conditions, and thus of the unconditioned, and his conception of systematic unity, especially when one keeps in mind that the kind of systematic unity in which reason is interested would include both logical conditioning relations in syllogisms and real conditioning relations in the form of a system of scientific laws. In particular, it is tempting to think that it is precisely reason's interest in finding the totality of conditions, both logical and real, that is supposed to bring about the kind of systematic unity that would offer it a satisfying 'resting place' (A 584 /B6I2) in the unconditioned. For, if we keep in mind the complex conditioning relations that reason is interested in, which may well go in every possible direction, we can see that in finding the totality of conditions, it would have found the unconditioned conditions that would deliver the kind of systematic unity that would render the world intelligible (or at least as intelligible as it turns out to be). If we accept this view of things, rather than thinking of reason's search for the unconditioned and its interest in systematic unity as standing in irremediable conflict, I would propose, as a friendly amendment of my own, that we think of them as essentially complementary.

\section{Reply to Konstantin Pollok}

In chapter II, in the context of highlighting the philosophical parallels between how the understanding legislates laws to nature and how reason legislates the moral law, I raised the historical question of whether the development of Kant's views on theoretical legislation in the first Critique and the Prolegomena led to his account of practical autonomy in the Groundwork. Though the philosophical parallels stand on their own, it would still be good if there were textual evidence that supported them. At the time, I did not think that there was conclusive textual evidence that could decide the matter. In his helpful comments, Konstantin Pollok makes a case in favour of the parallels I identified. Again, we have what appears to be a friendly amendment, and I happily accept it. 
The main question, I think, is simply how much support Pollok's argument can provide my interpretation. His argument has a textual and a philosophical side. The textual side is based on a I2-page draft for the Prolegomena in which Kant does not speak directly to the issue, but instead notes that the question 'How is a categorical imperative possible?' can be helpful in determining 'the real principle of morals', before then referring to 'the important problem of transcendental philosophy, which has a striking similarity with that of morals'. Though this passage does establish that Kant sees a similarity between his theoretical and practical philosophies, it does not explicitly state what that similarity is supposed to consist in. Could it be that both theoretical and practical philosophy have first principles? Or that both are rooted in our cognitive faculties? Or that sentiment plays an at best secondary role in establishing normative demands?

This is where the philosophical side of Pollok's argument is relevant. Here he suggests that it is the question of the possibility of synthetic a priori propositions that comes to play a bridging role in relating Kant's theoretical and practical philosophy after the first edition of the first Critique, when Kant was composing the Prolegomena and the Groundwork nearly simultaneously. Specifically, the idea is that, although the question of how synthetic a priori propositions are possible guided the development of Kant's thought since the early I770s, it was not until the Prolegomena that Kant took synthetic a priori propositions as central to metaphysics in both its theoretical and practical forms. Accordingly, if metaphysics (taken now in a positive sense, as contrasted with the dogmatic metaphysics Kant argued against in the Transcendental Dialectic) consists in fundamental (unconditioned) principles that are both synthetic and a priori, then it becomes plausible to think that there will be parallels in the explanations of the possibility of such principles in theoretical and practical philosophy. According to Pollok, because Kant comes to think that the understanding must legislate laws to nature for those laws to be synthetic a priori, he is led to think that reason must legislate laws to rational beings for the fundamental principle of morality to be synthetic a priori. In short, for Pollok what is crucial to metaphysics, whether it be theoretical or practical, is that its principles are synthetic a priori and that the possibility of such principles can be explained only by a non-empirical deduction, which will depend on acts of legislation, which will be either theoretical or practical, depending on the kind of principle at issue. And it is because of this fundamental philosophical situation that solving the problem with acts of legislation on the theoretical side in the Prolegomena led Kant to solve it on the practical side in the 
Groundwork with acts of legislation that must be 'strikingly similar' to the former.

Pollok's suggestion thus nicely puts a number of elements of Kant's view together in a potentially helpful way, one that seems to support the parallels that are most important to my overall thesis regarding the nature of law. At the same time, I do wonder whether the pieces fit together quite as neatly as Pollok suggests. The first point that gives me pause concerns the role that the synthetic a priori is supposed to play in Kant's theoretical philosophy. In the Prolegomena, Kant's fundamental question is whether metaphysics is possible as a science and to answer it he characterizes the claims of metaphysics as synthetic a priori because it allows him to compare the claims of metaphysics, whose status is unclear, with the claims of mathematics and the pure part of natural science, which similarly consist of synthetic a priori propositions but whose status as legitimate sciences is settled. As I understand the overall argument of the Prolegomena, the crucial point is that the problem with the claims of metaphysics is not that one cannot explain the synthetic a priori status of their judgements, but rather that, unlike the claims of mathematics and pure natural science, the claims of metaphysics cannot amount to cognition. Specifically, Kant needs to characterize the claims of metaphysics as synthetic, not because they are not really synthetic and the realization of that fact when one tries to explain their possibility leads him to reject them, but rather because the problems that he sees with the claims of metaphysics arise only for its synthetic claims, not for analytic claims, which are unproblematic. And the problems he then points out for this subset of claims concern whether they can be cognition in the robust sense applicable to the claims of mathematics and pure natural sciences. Pointing to the fact that there is a single question that frames Kant's discussion of both his theoretical and practical philosophies does not immediately entail structural parallels throughout (as a 'short argument' would hope), since one has to look to the specific arguments Kant gives to see how the larger framing question is to be answered in detail. ${ }^{8}$

Relatedly, when one turns to the connection between legislation and the possibility of the synthetic a priori judgements, the situation is no simple matter. For example, it would be too simple to claim that explaining the possibility in question is accomplished merely by appealing to acts of legislation. Take the case of mathematics. When Kant explains the possibility of mathematics as a body of synthetic a priori cognition, the central element of the explanans is contributed by space and time as a priori intuitions, which do not involve any act of legislation. Instead, it is 
tempting to think that the synthetic aspect of mathematical judgements is to be explained by the fact that our intuitions (along with the constructions that are possible only in pure intuition) derive from sensibility rather than our understanding, a fact that, if taken in isolation, could (misleadingly) suggest that acts of legislation are not even necessary for the synthetic a priori cognitions of mathematics. And even the case of pure natural science is not completely straightforward. Though Kant is committed to acts of legislation in this case, it is not obvious that these acts are what explain the synthetic character of the claims of pure natural science, as, once again, sensibility can seem to be necessary for such an explanatory role. Now, in this case, it is immediately clear that acts of legislation are necessary conditions for the claims of pure natural science, given that these claims assert laws which the understanding legislates to nature. But how exactly the understanding legislates the laws to what is given in intuition is of course far from simple and straightforward.

I mention these complications not because I want to raise significant doubts about Pollok's historical claim that Kant's views on theoretical legislation led to his views on practical legislation, but rather because I think it important to note that even after 297 pages and three additional insightful perspectives on these issues (along with my replies), the final word has not been spoken on these issues. In particular, as Pollok's comments have brought out more clearly, we still need a full and detailed explanation of how acts of legislation are involved in Kant's explanation of the synthetic status of the synthetic a priori principles that constitute the foundation of his metaphysics of nature and his metaphysics of morals. Though I have not highlighted the issue either in the book or in my present comments, it is also clear that we still need an account of how Kant thinks that laws are related to transcendental idealism. Is it the case that the laws that our cognitive faculties legislate must be transcendentally ideal, since they seem to exist only because of the act of legislation? Or must they be neutral on this question, since the moral law, which depends only on rationality and its acts of legislation, is not subject-dependent in the way that appearances are, as is clear from the fact that the moral law is as valid for God as it is for us, even if it does not take on imperatival form for God? Given the systematic and foundational role that laws play in Kant's philosophy, it is inevitable that more important issues involving laws remain to be clarified.

\section{Notes}

I Watkins (20I9). These comments were first presented in a book symposium organized by Marcus Willaschek and held online in July 2020. I am grateful to him and to all the 
participants (which included Marius Stan and Fabian Burt as well) for the productive exchange.

2 Translations of Kant's text are from the Cambridge Edition of the Works of Immanuel Kant (ed. by Paul Guyer and Allen Wood, Cambridge: Cambridge University Press, I992-). References to Kant's works are given using the volume and page number in the Akademie edition, Kants Gesammelte Schriften (ed. Königlich Preussische Akademie der Wissenschaften and successors, vols I-29, I900-).

3 For this point, see Ameriks (2003: 263-82) and Pollok (2017: 203-4).

4 Recall that in the Prolegomena Kant defines nature as 'the existence of things insofar as that existence is determined according to universal laws' $(P, 4: 294)$. Similarly, in the third section of the Groundwork of the Metaphysics of Morals, he defines freedom as 'a causality in accordance with immutable laws, but of a special kind' since 'the concept of causality brings with it that of laws' $(G, 4: 446)$.

5 See Ameriks (2017) and Pollok (2017).

6 Ameriks (20I7) acknowledges this point, and Pollok (2017) offers a detailed interpretation of legislation in part 3 of his book, esp. in chapter 6.

7 For a detailed account of how the form-matter distinction is relevant in this kind of context, see Pollok (2017).

8 For fuller discussion of Kant's project in the Prolegomena, see Watkins (forthcoming).

\section{References}

Ameriks, Karl (20I7) 'On Universality, Necessity, and Law in General in Kant'. In Michela Massimi and Angela Breitenbach (eds), Kant and the Laws of Nature (Cambridge: Cambridge University Press), 30-48.

Pollok, Konstantin (20I7) Kant's Theory of Normativity. Cambridge: Cambridge University Press.

Watkins, Eric (2005) Kant and the Metaphysics of Causality. Cambridge: Cambridge University Press.

(2019) Kant on Laws. Cambridge: Cambridge University Press.

(forthcoming) 'Is Metaphysics Possible? The Argumentative Structure of the Prolegomena'. In Peter Thielke (ed.), The Critique Guide to Kant's Prolegomena (Cambridge: Cambridge University Press). 